\title{
Intra- and postoperative catumaxomab in patients with epithelial ovarian cancer: safety and two-year efficacy results from a multicentre, single-arm, phase II study
}

\begin{abstract}
J Sehoulit, 1,2, A Reinthaller ${ }^{3}$, C Marth $^{4}$, D Reimer ${ }^{2}$, T Reimer ${ }^{5}$, W Stummvoll ${ }^{6, *}$, L Angleitner-Boubenizek ${ }^{6}$, B Brandt ${ }^{7}$ and R Chekerov ${ }^{2}$

${ }^{1}$ NOGGO, Ovarian cancer study group of the North-Eastern German Society of Gynaecological Oncology (NOGGO), Berlin, Germany; ${ }^{2}$ Department of Gynaecology, Charité University Hospital, Campus Virchow Clinic, Augustenburger Platz 1, 13353 Berlin, Germany; ${ }^{3}$ Department of Gynaecology and Gynecologic Oncology, Medical University of Vienna, Waehringer Guertel 18-20, A-1090 Vienna, Austria; ${ }^{4}$ Department of Obstetrics and Gynaecology, Innsbruck Medical University, Anichstraße 35, A-6020 Innsbruck, Austria; ${ }^{5}$ Department of Obstetrics and Gynaecology, Klinikum Suedstadt, University of Rostock, Südring 81, D-18059 Rostock, Germany; ${ }^{6}$ Department of Obstetrics and Gynaecology, Landesfrauenklinik Linz, Krankenhausstraße 26-30, A-4020 Linz, Austria and ${ }^{7}$ Neovii (formerly Fresenius) Biotech GmbH, Frankfurter Ring 193a, 80807 Munich, Germany
\end{abstract}

Background: This is the first study investigating the safety and efficacy of the trifunctional antibody catumaxomab administered i.p. at the end of cytoreductive surgery and postoperatively prior to standard chemotherapy in patients with primary epithelial ovarian cancer (EOC).

Methods: Patients received i.p. catumaxomab $10 \mu \mathrm{g}$ intraoperatively and 10, 20, 50 and $150 \mu \mathrm{g}$ on days 7, 10, 13 and 16, respectively, postoperatively. After the study, patients received standard chemotherapy and were followed for 23 months. The primary endpoint was the rate of postoperative complications.

Results: Forty-one patients entered the study and were evaluable for safety and 34 were alive at 24 months. Complete tumour resection rate was $68 \%$. Postoperative complications were observed in 51\%, the most common anastomotic leakage $(7 \%)$ and wound infections (5\%). The most common catumaxomab-related adverse events were abdominal pain, nausea, vomiting and pyrexia. Thirty-nine percent discontinued catumaxomab therapy, and $98 \%$ received chemotherapy post study. Kaplan-Meier estimates of disease-free and overall survival after 24 months were $56 \%$ and $85 \%$, respectively.

Conclusions: Intra- and close postoperative catumaxomab seems feasible, but efficacy and safety were limited by postsurgical complications. In the future prospective trials are needed to investigate the best schedule of integration of catumaxomab into current treatment strategies for EOC.

Ovarian cancer is associated with the highest mortality of any gynaecological cancer (Ferlay et al, 2013). At the time of diagnosis, epithelial ovarian cancer (EOC) mainly presents as advanced disease due to the lack or presence of non-specific symptoms in early stages of the disease (Aebi and Castiglione, 2009; Lutz et al, 2011). As a result, patients usually present with primary peritoneal carcinomatosis and malignant ascites (Woopen and Sehouli, 2009; Teo, 2010). The main histology of

*Correspondence: Professor J Sehouli; E-mail: jalid.sehouli@charite.de

Deceased.

Received 15 January 2013; revised 25 June 2014; accepted 13 July 2014; published online 16 September 2014

(c) 2014 Cancer Research UK. All rights reserved 0007 - 0920/14 
ovarian malignancies is epithelial, which accounts for $~ 90 \%$ of all cases (Lutz et al, 2011).

Standard treatment consists of cytoreductive surgery, aiming to reduce macroscopic intraabdominal spread, in combination with adjuvant chemotherapy, aiming to eliminate disseminated microscopic residuals. Based on this strategy, the complete remission rate is $\sim 75 \%$ with median disease-free survival (DFS) and overall survival (OS) of 15-21 and 24-66 months, respectively (Ozols, 2006). However, despite recent improvements in surgical and medical treatment, most patients will experience tumour relapse with multifocal peritoneal spread and die due to tumour progression (Sehouli et al, 2009). Current treatment strategies often fail to control substantially risk of recurrence, probably due to minimal residual disease inside the peritoneal cavity, which remain unaffected by systemic therapy (Chekerov et al, 2013). Thus there is an unmet clinical need to develop more effective treatment for advanced EOC. To improve patient outcome, a number of different strategies have been evaluated in the past decades, most of which included addition of third cytotoxic drug or dose-dense regimes. Recently moleculartargeted approaches, such as inhibition of angiogenesis, cell-cycle regulation, apoptosis, BRCA mutation status and protein expression are in the clinical focus (Bast, 2011; Tsujioka et al, 2011). Newly the anti-angiogenic agent bevacizumab has been shown to prolong PFS in advanced EOC (Monk et al, 2013).

A promising novel approach is the addition of immunotherapy to cytostatic therapy. The trifunctional antibody catumaxomab (anti-epithelial cell adhesion molecule $($ EpCAM) $\times$ anti-CD3; Removab; Neovii (formerly Fresenius) Biotech $\mathrm{GmbH}$, Munich, Germany) has shown efficacy in the i.p. treatment of malignant ascites from EpCAM-positive epithelial cancers including ovarian cancer leading to a prolonged puncture-free interval and puncturefree survival by efficient elimination of EpCAM-positive tumour cells inside peritoneal cavity (Burges et al, 2007; Heiss et al, 2010). Catumaxomab simultaneously binds to EpCAM-positive tumour cells, to $\mathrm{CD} 3+\mathrm{T}$ lymphocytes and to type I, IIa and III Fc $\gamma$-receptor-positive accessory cells (e.g., natural killer cells and macrophages), thereby inducing tumour-specific cytotoxicity (Zeidler et al, 1999; Ruf and Lindhofer, 2001; Ruf et al, 2007). Clinical trials identified i.p. catumaxomab as a tolerable new target agent with mostly mild to moderate and reversible toxicity (pyrexia, nausea and vomiting) based on its immunological mode of action (Burges et al, 2007; Heiss et al, 2010). Epithelial cell adhesion molecule is highly expressed in EOC (Heinzelmann-Schwarz et al, 2004; Went et al, 2004) and associated with reduced survival (Spizzo et al, 2006; Woopen and Sehouli 2009). Catumaxomab is approved for the treatment of patients with symptomatic malignant ascites, a typical feature of epithelial malignancies like EOC, who are commonly presenting with peritoneal carcinomatosis. Beside a specific antibody efficacy on malignant ascites various data suggest relevant systemic antitumor activity of catumaxomab (Burges et al, 2007; Heiss et al, 2010). Thus combination of catumaxomab with adjuvant cytostatic regimes is of special clinical interest.

The aim of this study was to evaluate the safety of one dose catumaxomab, administered intraoperatively at the end of surgery, and four postoperative doses, applied according to the approval recommendations (Burges et al, 2007; Heiss et al, 2010) prior to standard chemotherapy in patients with primary ovarian cancer. This is the first study investigating if the trifunctional antibody catumaxomab is feasible as partner to adjuvant treatment of patients with EOC who suffer from potential risk of peritoneal spread.

\section{PATIENTS AND METHODS}

Study design. This was an open-label, multicentre, single-arm, phase II study conducted 2007-2008 in six hospitals in Germany and Austria. During the primary cytoreductive surgery two port catheters were implanted intraabdominally and fixed in the subcutis. Treatment consisted of one intraoperative bolus catumaxomab $10 \mu \mathrm{g}$, administered directly into the peritoneal cavity before wound closure of primary cytoreductive laparotomy, followed by four i.p. doses of 10, 20, 50 and $150 \mu \mathrm{g}$ administered postoperatively via the i.p. ports as 3-hour infusions on days 7, 10, 13 and 16, respectively (Figure 1). Catumaxomab was diluted in $0.9 \%$ sodium chloride to 10,20 or $50 \mathrm{ml}$ according to approved recommendations (Burges et al, 2007; Heiss et al, 2010). To minimise cytokine-related reactions, paracetamol $1000 \mathrm{mg}$ was given $30 \mathrm{~min}$ before each dose (i.v. or orally). To enable optimal distribution of the study drug, $0.9 \%$ sodium chloride solution, $500 \mathrm{ml}$ was administered via the i.p. port before each infusion. If necessary, the time between two catumaxomab infusions could be prolonged by 4 days. The minimum allowable time interval between any two doses was 3 days and the total treatment period (from initial bolus to last i.p. dose) was not to exceed 21 days. Dose reductions were not allowed. An end-of-study (EOS) visit was performed on day 30 ( \pm 4 days), after which patients entered the post-study period during which they received six cycles of platinum-based chemotherapy. Patients were followed every 3 months after catumaxomab treatment for 23 months for a total study period of 24 months.

The study protocol, patient information and informed consent form were approved by the local ethics committee. Written informed consent was obtained from all patients before study entry. The study was designed in accordance with the Declaration of Helsinki, ICH-GCP guidelines and national law. EUDRACT number: 2006-004484-54.

Study objectives. The primary aim was to determine the safety of adjuvant catumaxomab, in terms of the postoperative complication rate as defined in the protocol. Secondary objectives were tolerability and feasibility of perioperative catumaxomab, graded according to NCI-CTC Criteria for Adverse Events (version 3.0, 2003), and preliminary efficacy assessed by DFS and OS after 24 months of observation.

Patients. Patients aged $\geqslant 18$ years with histologically confirmed EOC, including clear-cell carcinoma, FIGO stage IA (G2-G3)-IV and Karnofsky performance status $\geqslant 70$ were included in the study. As this was a feasibility study all patients planned for debulking surgery, signed an informed consent before intervention and was registered preoperatively. The final decision for catumaxomab application was performed intraoperatively by the treating physician, based on histological findings and on clinical presumption of high risk of i.p. cancer cell dissemination. Exclusion criteria included prior surgery; any type of medical therapy including treatment with non-humanised mouse or rat monoclonal antibodies for ovarian cancer; known or suspected hypersensitivity to catumaxomab or similar antibodies; the use of constant immunosuppressive therapy; symptomatic heart failure or occlusive arterial diseases; and inadequate renal (creatinine $>1.5 \times$ upper limit of normal (ULN)) or hepatic (aspartate aminotransferase or alanine aminotransferase $>2.5 \times$ ULN or bilirubin $\geqslant 1.5 \times$ ULN) function. Patients could be withdrawn from study treatment upon withdrawal of consent and at the discretion of the investigator that is due to adverse events (AEs), serious AEs (SAEs) or other toxicity, or in case of co-medication prohibited in this protocol, or any other deviations which the investigator judged to be relevant.

Postoperative complications and catumaxomab-associated AEs. All postoperative surgical and non-surgical complications observed between day 0 (surgical intervention) and EOS visit were documented as AEs on a daily basis in patients who received one or more doses of catumaxomab. One patient could develop 


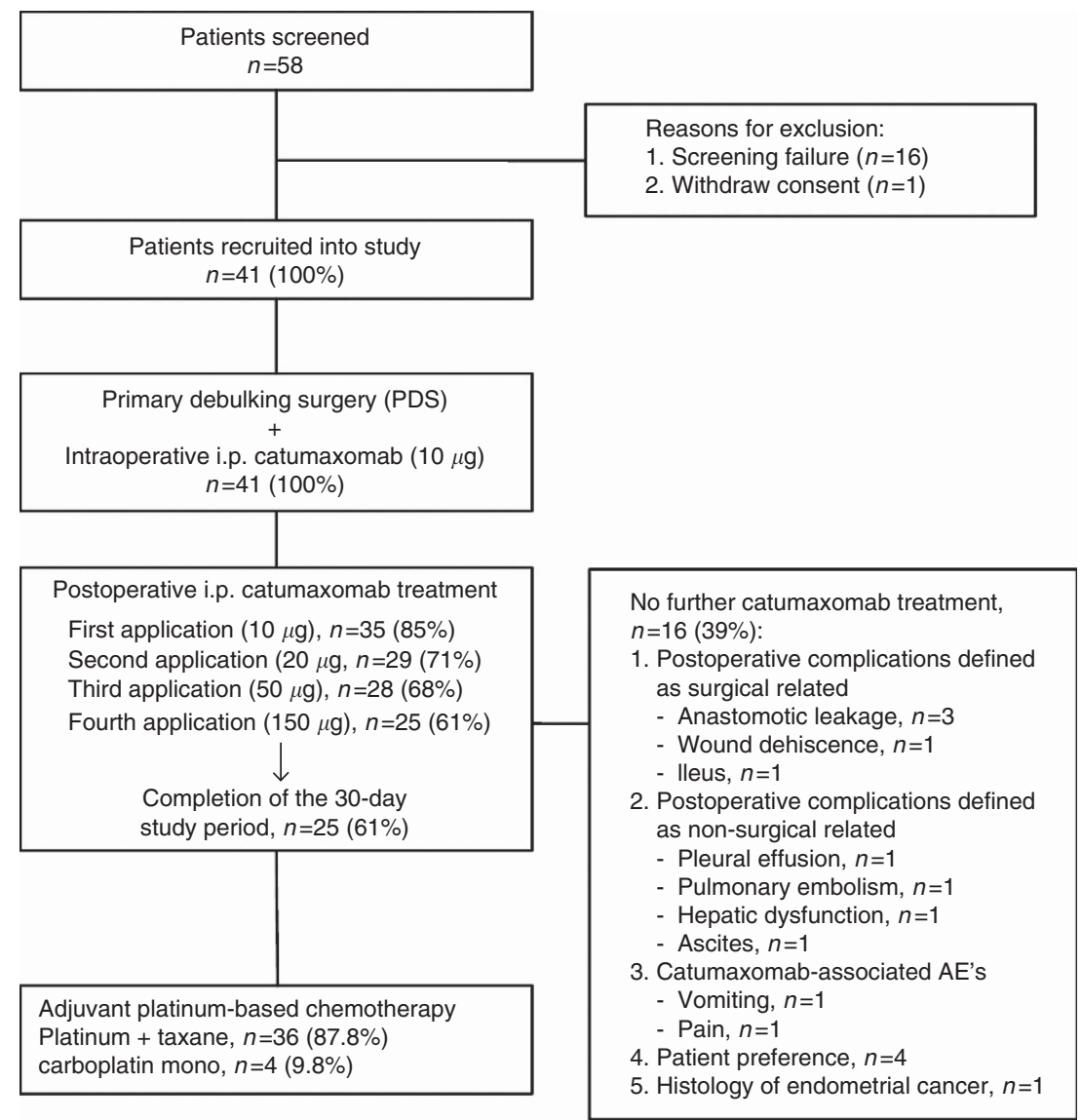

Figure 1. Consort diagram of study design.

more than one complication. A study-specific Data and Safety Monitoring Board (DSMB) evaluated all postoperative complications in a timely manner, as a risk of complications was to be expected due to the surgical character of the study. In order to differentiate between complications clearly related to surgery or to cancer disease two categories were predefined: surgical and non-surgical events. Surgical complications were defined as fistula, ileus, bowel perforation or anastomotic leakage requiring surgery, wound infection, haemorrhage requiring any therapy and septicaemia. Non-surgical complications were thromboembolism, infection CTC grade $\geqslant 3$, pleural effusion requiring puncture, renal insufficiency CTC grade $\geqslant 3$, liver failure, heart rhythm disorder requiring intervention, neurological disorder CTC grade $\geqslant 3$ and pulmonary oedema. Severity of the postoperative complications was evaluated according to the NCI-CTC system, version 3.0.

In addition, AEs associated to catumaxomab or its administration mode (catumaxomab-associated AEs (CAEs)) were analysed. Side effects caused by administration modalities were defined as i.p. catheter dislocation or dysfunction, local pain or erythema, extravasation, abdominal disorders associated with the i.p. infusion of $0.9 \%$ sodium chloride. catumaxomab-associated AEs resulted due to the characteristic immunological release of cytokines after catumaxomab application were pyrexia, chills, nausea, vomiting, hepatic, hepatobiliary and WBC disorders.

Statistical analysis. Statistical analyses were performed using the Statistical Analysis System (SAS) software package (version 9.1.3; SAS Institute Inc., Cary, NC, USA). Formal statistical hypothesis testing was performed on the primary endpoint (the rate of postoperative complications) and conducted at the one-sided 0.1 level of significance. All other statistical analyses were descriptive.

The statistical analysis regarding the postoperative complication rate was performed on the basis of monocentric observed complication rate of $28 \%$ at the Charite University Hospital of Berlin (documented complications of primary cytoreductive surgery in 244 patients with a confirmed primary diagnosis of EOC FIGO stage IA (G2-G3)-IV, April 2006). The following hypothesis was to be tested: $\mathrm{H}_{0}: \mathrm{c}>48 \%$ vs $\mathrm{H}_{1}: \mathrm{c}<28 \%$, where $\mathrm{c}$ is the postoperative complication rate. If the postoperative complication rate was $28 \%$ or lower, the regimen was suitable for further studies. If the postoperative complication rate was $\geqslant 48 \%$, the regimen was defined as not suitable for further studies. The target alpha level (probability of the wrong positive decision to continue with a high postoperative complication rate $(\geqslant 48 \%)$ ) was set at $10 \%$. The target beta level (probability of the wrong negative decision to stop with a small postoperative complication rate $(\leqslant 28 \%)$ ) was set at $10 \%$, corresponding to a power of $90 \%$. This study required 41 evaluable patients to determine the proportion of individuals with a postoperative complication rate of $\leqslant 28 \%$ or $\geqslant 48 \%$. Patients were considered evaluable if they received at least one dose of catumaxomab followed by chemotherapy. Criteria for efficacy assessment were defined according to institutional regulations and based on gynaecological examination with transvaginal ultrasound, CA 125, CT or MRI examinations.

Disease-free survival was calculated as the period between surgery and the date of documented relapse/progression or death. Overall survival was calculated from the date of surgery to the date of death. Patients without an event (relapse/progression or death) or who were lost to follow-up had their event time censored on the date of last contact. Disease-free survival and OS were calculated as crude rates with $95 \% \mathrm{CI}$ at 24 months. 


\section{RESULTS}

Patients. Fifty-eight individuals were screened, of whom 41 were included in the study, received at least one dose of the study drug in combination with surgery and were evaluable for safety. Sixteen patients were not included because of screening failure and one withdrew consent before surgery (Figure 1). All 41 evaluable patients were Caucasian with predominantly advanced stage FIGO high-risk II-IV (79\%) and serous papillary (70.8\%) EOC (Table 1). The most frequent surgical procedures included adnexectomy and omentectomy (both 93\%), hysterectomy (88\%), para-aortic $(81 \%)$ and pelvic lymphadenectomy (73\%). Twenty-four patients underwent subtotal peritonectomy (59\%) commonly combined with diaphragm surgery: diaphragm metastasis resection (17\%), partial diaphragm resection (12\%) and metastasis resection of the liver serosa (7\%). Bowel resections with consecutive anastomosis were performed in 18 patients (44\%). The macroscopic tumour-free resection rate was $68 \%$.

Of the 41 patients, who all started with the intraoperative dose of catumaxomab, $85 \%$ received also the second i.p. infusion, $71 \%$ the third, $68 \%$ the fourth and $61 \%$ received all five study drug infusions and completed the 30 -day study period. Sixteen patients (39\%) were excluded previously from further catumaxomab treatment. Nine patients $(22 \%)$ were withdrawn due to

Table 1. Patients' baseline characteristics and surgical outcome $(n=41)$

\begin{tabular}{|l|c|}
\hline Median age, years (range) & $57.8(33-75)$ \\
\hline FIGO stage, $\boldsymbol{n}(\%)$ & $8(20)$ \\
\hline$I^{\text {a }}$ & $2(5)$ \\
II & $26(63)$ \\
III & $4(10)$ \\
IV & $1(2)$ \\
Not assessed
\end{tabular}

\section{Grading, $n$ (\%)}

G1, well differentiated

G2, moderately differentiated

G3, poorly differentiated

Not assessed

$2(4.9)$

$11(26.8)$

$24(58.5)$

$4(9.8)$

\section{Histology, n (\%)}

Serous papillary

Mucinous

Endometrioid

Clear cell

$29(70.8)$

$3(7.3)$

$3(7.3)$

$1(2.4)$

Not documented

$5(12.2)$

\section{Karnofsky performance status, $\mathbf{n}(\%)$}

\begin{tabular}{|l|c}
$100 \%$ & $21(51)$ \\
$90 \%$ & $18(44)$ \\
$80 \%$ & $2(5)$
\end{tabular}

\section{Surgical outcome, n (\%)}

Complete tumour resection (no macroscopic disease)

$28(68)$

Suboptimal tumour debulking, residuals $\leqslant 1 \mathrm{~cm}$

$9(22)$

Gross residual tumour $>1 \mathrm{~cm}$

$4(10)$

Abbreviation: $\mathrm{FIGO}=$ Fédération Internationale de Gynécologie et d'Obstétrique.

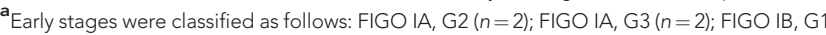
$(n=1)$; FIGO IC, G2 $(n=2)$; and FIGO IC, grading not assessed $(n=1)$. One patient was diagnosed with a serous papillary endometrial carcinoma after surgery and study drug application, G3 and FIGO stage was indicated as 'not assessable'; percentages do not always add up to $100 \%$ due to rounding. postoperative complications and two (5\%) due to CAEs, always on discretion of the investigator. Four participants (10\%) discontinued study drug treatment due to patient's preference, whereas for one patient (2\%) the final histology reported an endometrial carcinoma (see Figure 1).

Forty patients $(97.6 \%)$ received adjuvant chemotherapy for a median of six cycles (range 1-8 cycles) consisted of carboplatin or paclitaxel or a combination of both after the adjuvant application of catumaxomab (Figure 1). A complete response to platinumbased chemotherapy was reported for 19 patients (48\%), partial response for $2(5 \%)$, stable disease for $5(13 \%)$, progressive disease in 2 women (5\%), whereas $28 \%$ were not assessed for efficacy analyses during the 24-month follow-up period.

Safety. All patients who received one or more doses of catumaxomab were eligible for the safety analysis. The postoperative complication rate was $51 \%$ with 21 patients experiencing a per-protocol defined complication. The postoperative complications were much higher after the intraoperative i.p. catumaxomab dose (11 of 41 patients; $27 \%$ ), but decreased consecutively after the first (4 of 35 patients; 11\%) and second (1 of 29 patients; 3\%) postoperative i.p. infusions. No postoperative complications occurred after the third and fourth catumaxomab applications.

The most common postoperative surgical complications were anastomotic leakage (7\%) and wound infection (5\%). Fistula, ileus or haemorrhage requiring therapy was rare (every 2\%) (Table 2). According to the subgroup of 18 patients with bowel resection the rate of anastomotic leakage was $17 \%$. The most frequent postoperative non-surgical complications were pleural effusion, infections, thromboembolism and cardiac disorders. No patient experienced sepsis, severe renal insufficiency, liver failure or a fatal outcome.

Tolerability. Within the 41 patients overall of 153 doses of catumaxomab were applied via i.p. catheter (range 1-5). Thirtynine patients $(95 \%)$ developed one or more CAEs related to

Table 2. Postoperative complications occurred in 21 patients, $51 \%$ (safety analysis set, $n=41)^{a}$

\begin{tabular}{|l|l|l|}
\hline Postoperative complications & Patients, $n$ & $\%(95 \% \mathrm{Cl})$ \\
\hline
\end{tabular}

\section{Related to surgery ${ }^{b}$}

\begin{tabular}{|l|c|c|}
\hline Anastomotic leakage requiring surgery & 3 & $7(2-20)$ \\
\hline Wound infection & 2 & $5(0.6-17)$ \\
\hline Any fistula & 1 & $2(0.1-13)$ \\
\hline Ileus requiring any surgical therapy & 1 & $2(0.1-13)$ \\
\hline Haemorrhage requiring any therapy & 1 & $2(0.1-13)$
\end{tabular}

\section{Not related to surgery ${ }^{c}$}

\begin{tabular}{l|c|c|}
\hline Pleural effusion & 10 & $24(12-40)$ \\
\hline Infection grade $\geqslant 3$ & 8 & $20(9-35)$ \\
\hline Thromboembolism & 4 & $10(3-23)$ \\
\hline Cardiac disorder & 4 & $10(3-23)$ \\
\hline Neurological disorder grade $\geqslant 3$ & 1 & $2(0.1-13)$ \\
\hline $\begin{array}{l}\text { Abbreviation: } \mathrm{Cl}=\text { confidence interval. } \\
\text { a Patients were able to develop more than one complication. } \\
\text { bPostoperative complications defined as related to surgery: any fistula, ileus requiring any } \\
\text { surgical therapy, bowel perforation, anastomotic leakage insufficiency requiring surgery, } \\
\text { wound infection, haemorrhage requiring any therapy and septicaemia. } \\
\text { cPostoperative complications defined as not related to surgery: thromboembolism, } \\
\text { infection } \geqslant 3 \text { grade, pleural effusion requiring puncture, renal insufficiency } \geqslant \text { grade 3, liver } \\
\text { failure, heart rhythm disorder requiring intervention, neurological disorder } \geqslant \text { grade } 3 \text { and } \\
\text { pulmonary oedema. }\end{array}$
\end{tabular}


catumaxomab, with a total of 571 events reported (see Supplementary Table 1). The most common were pyrexia (73\%), abdominal pain (56\%), nausea (51\%) and vomiting (46\%; Table 3 ). Severe CAEs grade $\geqslant 3$ appeared in 23 patients (56\%): the most common were abdominal pain (12\%); pleural effusion (12\%) and gamma-glutamyltransferase (GGT) increase (10\%). Five grade 4 CAEs in three patients were reported: pleural effusion, GGT and blood amylase increase, and pulmonary embolism with acute respiratory distress syndrome, all of them leading to early study drug discontinuation.

In general the number of patients experiencing AEs and CAEs decreased during the i.p. catumaxomab treatment from the intraoperative (417 events) to the fourth postoperative infusion with 28 events (Table 3). No catumaxomab-related SAEs were reported during the follow-up period. Ten patients $(24 \%)$

Table 3. Tolerability profile according the catumaxomab-associated adverse events (CAEs) occurring in $\geqslant 5 \%$ of patients by preferred term (safety analysis set; $n=41$ )

Severe CAEs, $n(\%)$

\begin{tabular}{|l|c|c|c|}
\hline Adverse event & $\begin{array}{c}\text { CAEs, } \\
\text { n (\%) }\end{array}$ & $\begin{array}{c}\text { Grade } \\
\mathbf{3}\end{array}$ & $\begin{array}{c}\text { Grade } \\
4\end{array}$ \\
\hline Any catumaxomab-related AEs & $39(95)$ & $22(54)$ & $4(10)$ \\
\hline Pyrexia & $30(73)$ & - & - \\
\hline Abdominal pain & $23(56)$ & $5(12)$ & - \\
\hline Nausea & $21(51)$ & - & - \\
\hline Vomiting & $19(46)$ & $1(2)$ & - \\
\hline Fatigue & $14(34)$ & - & - \\
\hline Diarrhoea & $13(32)$ & $1(2)$ & - \\
\hline Pain & $13(32)$ & - & - \\
\hline C-reactive protein increase & $12(29)$ & $3(7)$ & - \\
\hline Pleural effusion & $11(27)$ & $4(10)$ & $1(2)$ \\
\hline Constipation & $8(20)$ & - & - \\
\hline Gamma-glutamyltransferase increase & $7(17)$ & $3(7)$ & $1(2)$ \\
\hline Aspartate aminotransferase increase & $6(15)$ & $1(2)$ & - \\
\hline Alkaline phosphatase increase & $6(15)$ & $1(2)$ & - \\
\hline Potassium decrease & $6(15)$ & - & - \\
\hline Oedema peripheral & $3(15)$ & - & - \\
\hline Procalcitonin increase & $3(7)$ & $3(7)$ & - \\
\hline Leukocyte count increase & $6(15)$ & $1(2)$ & - \\
\hline Alanine aminotransferase increase & $6(15)$ & $1(2)$ & - \\
\hline Dizziness & $5(12)$ & - & - \\
\hline Dyspnoea & $5(12)$ & - & - \\
\hline Flatulence & $5(12)$ & $1(2)$ & - \\
\hline Platelet count increased & $5(12)$ & - & - \\
\hline Activated partial thromboplastin time prolong & $5(12)$ & - & - \\
\hline Anaemia & $4(10)$ & - & - \\
\hline Back pain & $4(10)$ & $1(2)$ & - \\
\hline Lactate dehydrogenase increase & $4(10)$ & - & - \\
\hline Proteinuria & $3(2)$ & - \\
\hline Anastomotic leakage & $3(7)$ & - \\
\hline Amylase increase & - & $1(2)$ \\
\hline Chills & - & - \\
\hline Peritonitis & $3(10)$ \\
\hline
\end{tabular}

experienced 8 AEs and 17 SAEs that led to treatment discontinuation: anastomotic complications, peritonitis, vomiting, wound dehiscence and pleural effusion.

Efficacy. After 24 months of study observation and follow-up, DFS and OS were 54\% (95\% CI 37\%-69\%) and 85\% (95\% CI 71\%-94\%), respectively. Most patients (59\%) were relapse free after the 23 months of study follow-up. The 24-month DFS and OS of all patients with advanced stages FIGO III/IV were $40 \%$ and $80 \%$, respectively.

\section{DISCUSSION}

This is the first study investigating the trifunctional antibody catumaxomab given direct intraoperative at the end of primary debulking surgery (day 0) and followed by four postoperative infusions (on days 7,10,13 and 16) before platinum-based chemotherapy. Safety and tolerability profile was characterised by specific toxicity-like anastomotic leakage, wound complications, pleural effusion and infections, which resulted in 39\% discontinuation of study drug treatment, but without negative effect on adjuvant chemotherapy and patient outcome. Adjuvant catumaxomab seems attractive as immunological approach added before chemotherapy, but not clinically beneficial as perioperative combination, so that currently it could not be recommended for the treatment of primary ovarian cancer.

The reported complications pointed out some safety deficits of catumaxomab in the investigated adjuvant setting. Postsurgical severe AEs were frequent and resulted predominantly in study drug interruptions, reflecting complex tissue and immunological interactions described previously for other multi-target approaches mostly investigated in non-surgical trials (Burges et al, 2007; Kaye, 2007). With respect to the primary endpoint of this surgical study focused on safety of catumaxomab, the interpretation of the results is difficult and complex. First the antitumour cytotoxicity of catumaxomab leads to activation of T cells and accessory cells, and results in increased cytokine release that may have a systemic character (Ruf and Lindhofer, 2001). In addition, the majority of our patients were radically debulked, with common peritonectomy and bowel resections. Consequently most AEs occurred after the intraoperative application, decreasing further during the first two postoperative infusions and omitted completely after the third and fourth courses. This suggests that cytokines released by activated $\mathrm{T}$ cells and accessory cells may interact in a systemic inflammatory reaction probably similar to that found in severe infections (Zeidler et al, 1999; Burges et al, 2007). Finally although EpCAM was generally described as tumour cell localised, high expression levels were also detected in normal tissues of the gastrointestinal tract (Went et al, 2004). The possibility of increased absorption of catumaxomab after peritonectomy and lymph node resection should be also discussed, respecting the fact that systemic effects of anti-EpCAM-guided treatment on peritoneum or bowel epithelia in the close postsurgical phase were still not analysed. Thus our results are clinically important, helping to generate first prospective experience of catumaxomab in the close postsurgical adjuvant situation.

Excepting the critical first intraoperative catumaxomab dose, the further treatment with the trifunctional antibody presented similar tolerability profile as described (Heiss et al, 2010). The most common CAEs were disorders of gastrointestinal or general character or were direct associated to the administration mode (Table 3). Every patient developed some CAEs, but most of them were of moderate toxicity, like pyrexia, nausea, abdominal pain or vomiting, and were successfully resolved with standard analgesia, antipyretics or antiemetics. Our results support the experience that class-specific AEs of anti-EpCAM therapy are safe and could be easily managed by experienced physicians. 
The great challenge in ovarian cancer treatment is how to reduce risk of recurrence avoiding consequently multiple palliative treatments with shorter intervals of remission until development of multidrug resistance (Ozols, 2006). Optimal cytoreduction is the strongest prognostic factor for outcome, but the role of minimal residual disease represented by disseminated cancer cells surviving primary treatment inside the peritoneal cavity is still not clear (du Bois et al, 2009; Chang et al, 2013; Chekerov et al, 2013). Different strategies focused on the use of i.p. active drugs to reduce recurrence, but beside increased toxicity no significant efficacy benefits were obtained (Chan et al, 2012; Grabowski et al, 2012). As surgery is essential new targeted strategies should not compromise its prognostic impact. That is why we focused as primary endpoint on the postsurgical complications, because of their key role for patients' outcome. The obtained higher rate of surgical-related AEs like anastomotic leakage, infections or pleural effusions, could be identified as related to radical surgery and were described in the literature (Chan et al, 2012; Grabowski et al, 2012; Rafii et al, 2012). Severe peritoneal complications like paralytic ileus of fistula were not significantly increased in our observations (Sehouli et al, 2009; Rafii et al, 2012). Thus accumulation of surgical risk factors with possibly compromised postsurgical immunological status might be an explanation for the increased complication rate. We believe that anti-EpCAM/anti-CD3 therapy should not be recommended without precise preselection of the patients.

From the clinical point of view a relevant question is how worth could be the adjuvant implementation of catumaxomab. Clinical outcome in our population was promising although long-term survival data were limited. After the 24-month observation period overall DFS and OS were $54 \%$ and $85 \%$, respectively, showing no compromise in patients' outcome despite high rate of study drug interruptions (du Bois et al, 2009; Grabowski et al, 2012). However, our results need to be interpreted with caution as this study was non-randomised, had a small number of patients and with limited follow-up.

The critical role of the postsurgical period for morbidity and outcome is well known (Kaye, 2007; Grabowski et al, 2012; Rafii et al, 2012). Different predictors of higher risk of surgical complications and outcome are in discussion, but only partly prospectively evaluated (Sehouli et al, 2009; Grabowski et al, 2012; Rafii et al, 2012). Thus identification of risk factors that may compromise immunological status seems crucial for the successful implementation of catumaxomab. Extended abdominal or bowel surgery, AS also severe co-morbidities could be discussed as negative predicting factors for close intra- and postoperative treatment with catumaxomab. Our data support the conventional application of catumaxomab after upfront surgery and before adjuvant chemotherapy. Future investigation of catumaxomab in prospective studies focusing on optimisation of therapy schedule and targeting well-selected population is warranted.

\section{ACKNOWLEDGEMENTS}

The study was sponsored by Neovii Biotech GmbH and supported by the North-Eastern German Society of Gynecological Oncology (NOGGO). The authors would like to thank the freelance medical writer Kevin De-Voy (funded by Neovii Biotech $\mathrm{GmbH}$ ) for his writing support.

\section{CONFLICT OF INTEREST}

JS has received research funding from Neovii Biotech and acted as an advisor for Neovii Biotech, Boehringer Ingelheim, GlaxoSmithKline and Roche. BB is an employee of Neovii Biotech. The remaining authors declare no conflict of interest.

\section{REFERENCES}

Aebi S, Castiglione M. On behalf of the ESMO Guidelines Working Group (2009) Newly and relapsed epithelial ovarian carcinoma: ESMO Clinical Recommendations for diagnosis, treatment and follow-up. Ann Oncol 20(Suppl 4): 21-23.

Bast Jr RC (2011) Molecular approaches to personalizing management of ovarian cancer. Ann Oncol 22(Suppl 8): viii5-viii15.

Burges A, Wimberger P, Kümper C, Gorbounova V, Sommer H, Schmalfeldt B, Pfisterer J, Lichinitser M, Makhson A, Moiseyenko V, Lahr A, Schulze E, Jäger M, Ströhlein MA, Heiss MM, Gottwald T, Lindhofer H, Kimmig R (2007) Effective relief of malignant ascites in patients with advanced ovarian cancer by a trifunctional anti-EpCAM $\mathrm{x}$ anti-CD3 antibody: a phase I/II study. Clin Cancer Res 13: 3899-3905.

Chan DL, Morris DL, Rao A, Chua TC (2012) Intraperitoneal chemotherapy in ovarian cancer: a review of tolerance and efficacy. Cancer Manag Res 4: 413-422.

Chang SJ, Hodeib M, Chang J, Bristow RE (2013) Survival impact of complete cytoreduction to no gross residual disease for advanced-stage ovarian cancer: a meta-analysis. Gynecol Oncol 130: 493-498.

Chekerov R, Braicu I, Castillo-Tong DC, Richter R, Cadron I, Mahner S, Woelber L, Marth C, Van Gorp T, Speiser P, Zeillinger R, Vergote I, Sehouli J (2013) Outcome and clinical management of 275 patients with advanced ovarian cancer International Federation of Obstetrics and Gynecology II to IV inside the European Ovarian Cancer Translational Research Consortium-OVCAD. Int J Gynecol Cancer 23: 268-275.

du Bois A, Reuss A, Pujade-Lauraine E, Harter P, Ray-Coquard I, Pfisterer J (2009) Role of surgical outcome as prognostic factor in advanced epithelial ovarian cancer: a combined exploratory analysis of 3 prospectively randomized phase 3 multicenter trials: by the Arbeitsgemeinschaft Gynaekologische Onkologie Studiengruppe Ovarialkarzinom (AGOOVAR) and the Groupe d'Investigateurs Nationaux Pour les Etudes des Cancers de l'Ovaire (GINECO). Cancer 115: 1234-1244.

Ferlay J, Steliarova-Foucher E, Lortet-Tieulent J, Rosso S, Coebergh JW, Comber H, Forman D, Bray F (2013) Cancer incidence and mortality patterns in Europe: estimates for 40 countries in 2012. Eur J Cancer 49: 1374-1403.

Grabowski JP, Harter P, Hils R, Lorenz D, Kaub C, Barinoff J, Heitz F, Traut A, du Bois A (2012) Outcome of immediate re-operation or interval debulking after chemotherapy at a gynecologic oncology center after initially incomplete cytoreduction of advanced ovarian cancer. Gynecol Oncol 126: 54-57.

Heinzelmann-Schwarz VA, Gardiner-Garden M, Henshall SM, Scurry J, Scolyer RA, Davies MJ, Heinzelmann M, Kalish LH, Bali A, Kench JG, Edwards LS, Vanden Bergh PM, Hacker NF, Sutherland RL, O'Brien PM (2004) Overexpression of the cell adhesion molecules DDR1, claudin 3, and Ep-CAM in metaplastic ovarian epithelium and ovarian cancer. Clin Cancer Res 10: 4427-4436.

Heiss MM, Murawa P, Koralewski P, Kutarska E, Kolesnik OO, Ivanchenko VV, Dudnichenko AS, Aleknaviciene B, Razbadauskas A, Gore M, Ganea-Motan E, Ciuleanu T, Wimberger P, Schmittel A, Schmalfeldt B, Burges A, Bokemeyer C, Lindhofer H, Lahr A, Parsons SL (2010) The trifunctional antibody catumaxomab for the treatment of malignant ascites due to epithelial cancer: results of a prospective randomized phase II/III trial. Int J Cancer 127: 2209-2221.

Kaye SB (2007) Bevacizumab for the treatment of epithelial ovarian cancer: will this be its finest hour? J Clin Oncol 25: 5150-5152.

Lutz AM, Willmann JK, Drescher CW, Ray P, Cochran FV, Urban N, Gambhir SS (2011) Early diagnosis of ovarian carcinoma: is a solution in sight? Radiology 259: 329-345.

Monk BJ, Dalton H, Farley JH, Chase DM, Benjamin I (2013) Antiangiogenic agents as a maintenance strategy for advanced epithelial ovarian cancer. Crit Rev Oncol Hematol 86: 161-175.

Ozols RF (2006) Challenges for chemotherapy in ovarian cancer. Ann Oncol 17(Suppl 5): v181-v187.

Rafii A, Stoeckle E, Jean-Laurent M, Ferron G, Morice P, Houvenaeghel G, Lecuru F, Leblanc E, Querleu D (2012) Multi-center evaluation of post-operative morbidity and mortality after optimal cytoreductive surgery for advanced ovarian cancer. PLoS One 7(7): e39415.

Ruf P, Gires O, Jäger M, Fellinger K, Atz J, Lindhofer H (2007) Characterisation of the new EpCAM-specific antibody HO-3: implications for trifunctional antibody immunotherapy of cancer. Br J Cancer 97: 315-321. 
Ruf P, Lindhofer H (2001) Induction of a long-lasting antitumor immunity by a trifunctional bispecific antibody. Blood 98: 2526-2534.

Sehouli J, Senyuva F, Fotopoulou C, Neumann U, Denkert C, Werner L, Gülten OO (2009) Intra-abdominal tumor dissemination pattern and surgical outcome in 214 patients with primary ovarian cancer. J Surg Oncol 99: 424-427.

Spizzo G, Went P, Dirnhofer S, Obrist P, Moch H, Baeuerle PA, Mueller-Holzner E, Marth C, Gastl G, Zeimet AG (2006) Overexpression of epithelial cell adhesion molecule (Ep-CAM) is an independent prognostic marker for reduced survival of patients with epithelial ovarian cancer. Gynecol Oncol 103: 483-488.

Teo M (2010) Peritoneal-based malignancies and their treatment. Ann Acad Med Singapore 39: 54-57.

Tsujioka H, Yotsumoto F, Hikita S, Ueda T, Kuroki M, Miyamoto S (2011) Targeting the heparin-binding epidermal growth factor-like growth factor in ovarian cancer therapy. Curr Opin Obstet Gynecol 23: 24-30.
Went PT, Lugli A, Meier S, Bundi M, Mirlacher M, Sauter G, Dirnhofer S (2004) Frequent EpCam protein expression in human carcinomas. Hum Pathol 35: 122-128.

Woopen H, Sehouli J (2009) Current and future options in the treatment of malignant ascites in ovarian cancer. Anticancer Res 29: 3353-3359.

Zeidler R, Reisbach G, Wollenberg B, Lang S, Chaubal S, Schmitt B, Lindhofer H (1999) Simultaneous activation of T cells and accessory cells by a new class of intact bispecific antibody results in efficient tumor cell killing. J Immunol 163: 1246-1252.

This work is published under the standard license to publish agreement. After 12 months the work will become freely available and the license terms will switch to a Creative Commons AttributionNonCommercial-Share Alike 3.0 Unported License.

Supplementary Information accompanies this paper on British Journal of Cancer website (http://www.nature.com/bjc) 